\title{
Effect of the oestrous cycle, pregnancy and uterine region on the responsiveness of the isolated mouse uterus to prostaglandin $F_{2 \alpha}$ and the thromboxane mimetic U46619
}

\author{
A L Griffiths, K M Marshall, J Senior, C Fleming \\ and D F Woodward ${ }^{1}$ \\ School of Pharmacy, University of Bradford, Bradford, West Yorkshire BD7 1DP, UK \\ ${ }^{1}$ Department of Biological Sciences, Allergan Inc., Irvine, California, USA \\ (Requests for offprints should be addressed to K M Marshall; Email: k.m.marshall@bradford.ac.uk)
}

\begin{abstract}
Previous studies in this laboratory have suggested that the isolated uterus from non-pregnant mice has a prostaglandin $\mathrm{F}$ and a thromboxane receptor population similar to that found in human myometrium. The aim of this study was to investigate any regional variation in myogenic activity and responsiveness to prostaglandin $\mathrm{F}_{2 \alpha}\left(\mathrm{PGF}_{2 \alpha}\right)$ and the thromboxane mimetic U46619 in the mouse uterus taken during different stages of the oestrous cycle and during pregnancy. Uterine samples from BKW mice were taken from different anatomical segments along the length of each uterine horn and set up for superfusion at $2 \mathrm{ml} / \mathrm{min}$ with Krebs solution (containing $1 \mu \mathrm{M}$ indometacin) at $37^{\circ} \mathrm{C}$, and gassed with $95 \% \mathrm{O}_{2} / 5 \% \mathrm{CO}_{2}$. Responses (area under the curve) are expressed as a percentage of the final contraction induced by hypotonic shock. Data are expressed
\end{abstract}

as the means \pm S.E.M.of $n=5-12$ and were analysed using Student's paired $t$-test or two-way ANOVA with a Bonferroni post hoc test. Regional variation in myogenic activity was observed in all tissues studied except those taken during labour. These tissues displayed significantly greater myogenic activity than tissues taken at late gestation and at all stages of the oestrous cycle. Tissues from pregnant animals were generally more responsive to $\mathrm{U} 46619$ and $\mathrm{PGF}_{2 \alpha}$ than tissues taken from non-pregnant animals. Tissues taken from the upper segment of the uterine horn were more responsive to both agonists during the oestrous cycle. The findings demonstrated that the hormonal milieu and site of excision are important for myogenic activity and responsiveness.

Journal of Endocrinology (2006) 188, 569-577

\section{Introduction}

Prostaglandins are involved in several reproductive processes in mice including ovulation, fertilization, luteolysis and modulation of uterine contractions (Sales et al. 1992). The importance of prostaglandins and their receptors in reproductive function has been determined in studies using knockout mice (Tsuboi et al. 2002), which show that prostaglandin F (FP) receptor-deficient mice exhibited failed parturition and prostaglandin E (EP) receptor-deficient mice have a decreased litter size. Thromboxane (TP) receptor knockout mice did not show any reproductive abnormalities (Thomas et al. 1998). The following mouse prostaglandin receptors have been isolated and cloned: prostaglandin D (Hirata et al. 1994), $\mathrm{EP}_{1}$ (Watabe et al. 1993), $\mathrm{EP}_{2}$ (Honda et al. 1993), $\mathrm{EP}_{3}$ (Sugimoto et al. 1992), $\mathrm{EP}_{4}$ (Nishigaki et al. 1995), FP (Sugimoto et al. 1994), prostaglandin I (Namba et al. 1994) and TP (Namba et al. 1992).

Previous studies in this laboratory have suggested that the uterus from the non-pregnant mouse has a similar
TP receptor and FP receptor population (Kennedy et al. 1994, Hutchinson et al. 2003) to that found in the non-gestational human myometrium (Senior et al. 1992). However, the potential effect of the oestrous cycle on the prostaglandin receptor profile has not been investigated. During the oestrous cycle, oestrogen and progesterone levels vary with the stage of the cycle (Walmer et al. 1992). Variations in oestrogen and progesterone ratio will affect myogenic activity and may also alter agonist responses. The FP receptor has been reported to be upregulated towards term in the human (Brodt-Eppley \& Myatt 1999) and mouse myometrium (Cook et al. 2003); however, an increase in the TP receptor population has not been reported.

To our knowledge, the topographical distribution of the FP and TP receptors in the mouse uterus has not been explored. In studies using isolated tissue the anatomical region of the uterus used should be considered. Studies using uterus from the non-pregnant rat have shown that the upper (ovarian) portion of the uterus is more sensitive to prostaglandin $\mathrm{F}_{2 \alpha}\left(\mathrm{PGF}_{2 \alpha}\right)$ than the lower (cervical) 
portion (Oropeza et al. 2000). Myogenic activity in the rat has been investigated during gestation and parturition and an increase in activity from late gestation through to labour has been shown; this study also observed regional variation in activity at late gestation (Fuchs 1969). Regional variation in responsiveness to $\mathrm{PGF}_{2 \alpha}$ has also been observed in human myometrium taken during labour, with the lower segment showing little responsiveness to $\mathrm{PGF}_{2 \alpha}$ (Wikland et al. 1984). However, the population of TP receptors is purported to be functionally homogenous throughout the human myometrium (Senchyna \& Crankshaw 1999).

This study was designed to investigate any regional variation in myogenic activity and responsiveness to $\mathrm{PGF}_{2 \alpha}$ and the stable thromboxane mimetic U46619 (Abramovitz et al. 2000) in the mouse uterus taken during different reproductive stages of the oestrous cycle and during pregnancy. This work is part of a larger on-going project and is running concurrently with similar experiments using human tissue; a subsidiary aim is to determine the suitability of the mouse for future in vivo studies.

\section{Materials and Methods}

\section{Tissue preparation}

Non-pregnant and pregnant female, sexually mature, BKW mice (B\&K Universal Ltd, Hull, Humberside, UK) housed in groups were used throughout this study. Experiments were carried out in accordance with the Animals Scientific Procedures Act 1986. The animals had free access to food and water and were exposed to a $12 \mathrm{~h}$ light: $12 \mathrm{~h}$ darkness cycle. Animals were mated in a harem of three females to one male. The presence of a vaginal plug was taken as evidence of pregnancy; the day of plug detection was termed day 1 of gestation. The mice were regularly weighed to monitor the progression of pregnancy.

The mice were killed by cervical dislocation when not pregnant, at day 18 of gestation (late gestation) or during labour. Animals killed during parturition were killed after delivery had initiated and usually after at least two pups had been delivered. In non-pregnant animals, the stage of the oestrous cycle was determined by microscopic examination of the vaginal lavage (Fox \& Laird 1970). The uterus was dissected from the body and uterine smooth muscle samples $(8-10 \mathrm{~cm}$ in length and $2-3 \mathrm{~cm}$ in width) were taken from along the length of each uterine horn. Uterine samples from non-pregnant animals were cut transversely to leave two tube-like pieces of tissue. Samples taken from pregnant and labouring animals were cut parallel to the longitudinal fibres along the length of the uterus. These samples were taken from four anatomical regions of the horn, one immediately above the cervix (lower), two from the middle portion, one being nearer the cervical end and the other from the ovarian end, and the last sample was taken from the uppermost section of the horn, directly below the ovary. In pregnant and labouring animals, the foetuses and placentae were completely removed from the uterus and foetuses were killed by carbon dioxide inhalation.

Uterine samples were immediately placed in oxygenated Krebs solution and set up for superfusion at a rate of $2 \mathrm{ml} / \mathrm{min}$. The strips were attached to an isometric force transducer and a resting tension of $2 \mathrm{~g}$ (Chen et al. 2001) was applied for superfusion with oxygenated Krebs (95\% $\mathrm{O}_{2} / 5 \% \quad \mathrm{CO}_{2}$ ) (Senior et al. 1991) containing $1 \mu \mathrm{M}$ indometacin (Duckworth et al. 2002) at $37^{\circ} \mathrm{C}$. Tissues were left for $30 \mathrm{~min}$ to equilibrate.

The prostanoid agonists were administered as $10 \mu \mathrm{l}$ bolus doses injected directly, through self-sealing silicone tubing, into the superfusate using a micropipette. Agonists were administered immediately after a spontaneous contraction to avoid superimposing responses on background activity; this did not apply if there was no background activity present. Responses were also investigated in the presence of $0 \cdot 1 \mu \mathrm{M}$ SQ29548, a thromboxane receptor antagonist (Ogletree et al. 1985). Only one dose-response curve was performed on each tissue.

At the end of each experiment the superfusate was changed from Krebs solution to distilled water. The infusion of distilled water induced a large contraction of the tissue (hypotonic shock) (Crankshaw 2001), which was unique to that particular myometrial strip; this was used as a reference contraction. No differences in hypotonic shock were observed between the different reproductive states.

\section{Measurement of responses}

The activity of the myometrial strips was measured via isometric force transducers linked to PowerLab hardware (AD Instruments Pty Ltd). Powerlab was linked to a PC (Dell Inc.) where Chart for windows 5 (AD Instruments Pty Ltd, Chalgrove, Oxfordshire, UK) was used to display and measure the tension changes in the tissue. A 10-min period after drug administration was measured (area under the curve) and expressed as a percentage of the hypotonic shock reference contraction. Data are expressed as the means \pm S.E.M.

\section{Compounds used}

Indometacin was obtained from Sigma-Aldrich Chemical Co., $\mathrm{PGF}_{2 \alpha}$, U46619 $\left(11 \alpha, 9 \alpha\right.$-epoxymethano $\left.\mathrm{PGH}_{2}\right)$ and SQ29548 ([1S-[1 $\alpha, 2 \alpha(Z), 3 \alpha, 4 \alpha]]-7-[3-[[2-[($ phenylamino)-

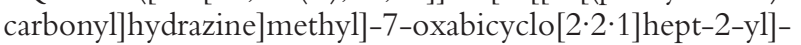
5 -heptenoic acid) were acquired from Cayman Chemical (distributed by Alexis Corporation (UK) Ltd, Bigham, Notts, UK). Indometacin, $\mathrm{PGF}_{2 \alpha}$ and SQ29548 were dissolved in ethanol and U46619 in methyl acetate. 


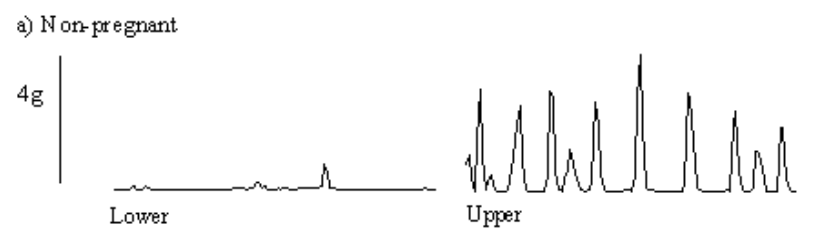

$\Rightarrow$ Labour

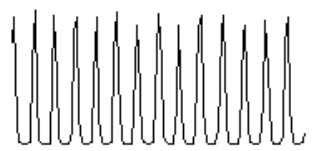

Lower

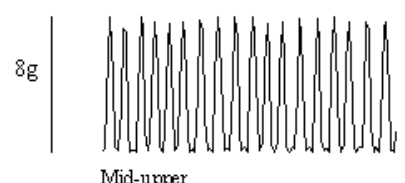

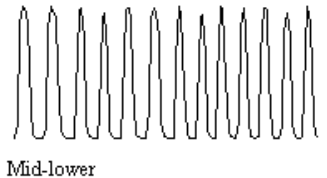

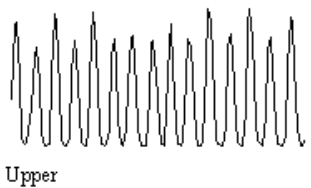

b) Late gestation
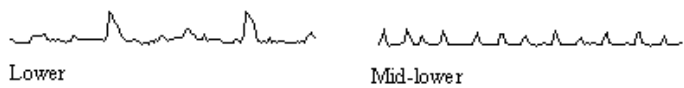

$5 \mathrm{~g}$

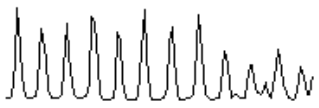

Mid-upper
Mid-lower

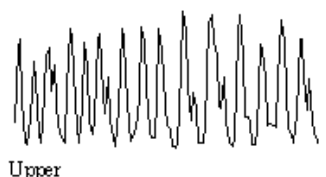

Figure 1 Typical traces (shown for $10 \mathrm{~min}$ ) to demonstrate the spontaneous activity of isolated mouse uterine tissue taken from different anatomical locations during (a) dioestrus, (b) late gestation and (c) labour.

Dilutions were made with $0.9 \%(\mathrm{w} / \mathrm{v})$ normal saline. The vehicles (matched for solvent) were found to have had no effect on myogenicity.

\section{Statistical analysis}

Data are expressed as the means \pm S.E.M. Statistical analysis of differences between two means was assessed by Student's $t$-test. Multiple means were compared by a twoway ANOVA with a Bonferroni post hoc test (GraphPad Prism 4.0, San Diego, CA, USA). A probability level of $P<0.05$ was regarded as significant.

\section{Results}

Effect of region of excision and reproductive state on myogenic activity

All mouse uterine samples displayed spontaneous myogenic activity (Fig. 1). Uterine tissues taken at late gestation or from a non-pregnant animal showed variable activity that started to decline after $60 \mathrm{~min}$. Large, sustainable, frequent contractions were observed in uterine tissue taken during labour. Uterine tissue taken from nonpregnant mice displayed regional variation in myogenic activity at all stages of the oestrous cycle (Fig. 1a and Table 1). The upper segment of the uterine horn displayed significantly greater activity compared with the lower segment at pro-oestrus $(P<0 \cdot 001)$, metoestrus $(P<0 \cdot 05)$ and dioestrus $(P<0 \cdot 001)$, but not during oestrus. Myogenic activity was found to vary along the length of the uterine horn in late gestation (Fig. 1b), with the upper segment being significantly more active compared with the lower $(P<0 \cdot 01)$ and mid-lower $(P<0 \cdot 05)$ segments (Table 1$)$. The activity of tissue excised during labour was constant along the length of the horn (Fig. 1c).

Variations in activity were also observed between the different endocrine stages; tissue taken during labour displayed significantly greater myogenic activity compared with equivalent tissue taken at late gestation $(P<0 \cdot 001$, lower and mid-lower; $P<0 \cdot 01$, mid-upper and upper). Tissue taken during labour was also more active than tissue taken from non-pregnant mice $(P<0 \cdot 001)$ (Table 1). Lower segment tissue taken during pro-oestrus showed significantly greater myogenic activity than uterine tissue taken during metoestrus $(P<0 \cdot 01)$, dioestrus $(P<0 \cdot 001)$ and late gestation $(P<0 \cdot 05)$ (Table 1$)$. Lower segment tissue taken during oestrus displayed significantly greater myogenic activity than tissue taken during dioestrus $(P<0 \cdot 05)$ (Table 1).

\section{Effect of U46619 on myogenic activity}

The TP-mimetic U46619 induced dose-related excitatory responses on all uterine tissues (Figs 2 and 3a). These responses were attenuated in the presence of SQ29548 (Fig. 3b). SQ29548 caused a significant rightward shift of all dose-response curves; $P<0.05$ to $P<0.001$ (data not shown). As can be seen from Fig. 2(a-d), U46619 evoked a greater response in tissue from the upper segment, but this difference only became significant $(P<0 \cdot 05)$ at the highest dose during dioestrus (Fig. 2d). At late gestation, regional variations in the response to U46619 were also observed (Fig. 2e). The maximum response achieved with U46619 increased progressively as segments became closer to the ovarian end of the horn, with a significantly greater 
Table 1 Spontaneous myogenic activity measured for $10 \mathrm{~min}$ (after a 30-min equilibration period) expressed as a percentage of a reference contraction induced by the infusion of distilled water (hypotonic shock). Data are expressed as arithmetic means \pm S.E.M. $n=10-12$

\begin{tabular}{|c|c|c|c|c|}
\hline & Lower segment & Mid-lower segment & Mid-upper segment & Upper segment \\
\hline Pro-oestrus & $12 \cdot 6 \pm 2 \cdot 3^{a}$ & N/D & $N / D$ & $43 \cdot 4 \pm 5 \cdot 2^{* * *}$ \\
\hline Oestrus & $14 \cdot 4 \pm 4 \cdot 9^{b}$ & $\mathrm{~N} / \mathrm{D}$ & $\mathrm{N} / \mathrm{D}$ & $28 \cdot 9 \pm 6 \cdot 4$ \\
\hline Metoestrus & $4 \cdot 2 \pm 0 \cdot 9$ & N/D & $\mathrm{N} / \mathrm{D}$ & $26 \cdot 2 \pm 7 \cdot 2^{*}$ \\
\hline Late gestation & $4 \cdot 7 \pm 0 \cdot 6$ & $15 \cdot 6 \pm 3 \cdot 5$ & $35 \cdot 5 \pm 13 \cdot 6$ & $50 \cdot 9 \pm 10 \cdot 2^{\star *}$ \\
\hline Labour & $78 \cdot 1 \pm 15 \cdot 4^{\mathrm{c}, \mathrm{d}}$ & $108 \cdot 5 \pm 15 \cdot 1^{d}$ & $110 \cdot 5 \pm 18 \cdot 6^{\mathrm{e}}$ & $108 \cdot 3 \pm 22 \cdot 9^{\mathrm{c}, \mathrm{e}}$ \\
\hline
\end{tabular}

N/D, not determined. In non-pregnant samples the upper and lower segment values are compared using a Student's paired $t$-test. In gestational samples the lower, mid-lower, mid-upper and upper segments were all compared with each other using a two-way ANOVA with a Bonferroni post hoc test.

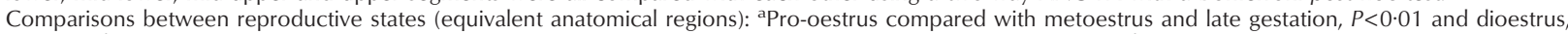
$P<0.001 ;{ }^{b}$ oestrus compared with dioestrus, $P<0.05$; Clabour compared with all non-pregnant groups, $P<0.001$; ${ }^{\text {,elabour }}$ compared with late gestation, ${ }^{\mathrm{d}} P<0 \cdot 001,{ }^{e} P<0 \cdot 01$. Comparisons between anatomical regions (same endocrine stage); ${ }^{*}$ upper compared with lower segment, $P<0 \cdot 05 ;{ }^{*}$ upper compared with lower, $P<0 \cdot 01$ and mid-lower $P<0 \cdot 05 ;{ }^{* * *}$ upper compared with lower, $P<0 \cdot 001$.

response being seen in the upper segment compared with the lower $(P<0 \cdot 001)$ and mid-lower $(P<0 \cdot 05)$ segment. A significantly greater response was seen in the mid-upper segment compared with the lower segment $(P<0 \cdot 01)$ (Fig. 2e). This pattern was not observed in tissue taken during labour (Fig. 2f) and the maximum responses attained during labour were attenuated compared with those in late gestation (Table 2); however, these trends were not statistically significant.

Variations in responses were also observed between the different reproductive states; in the upper segment tissue taken at late gestation U46619 evoked a greater response than at oestrus and metoestrus $(P<0 \cdot 01)$ (Table 2$)$.

\section{Effect of $\mathrm{PGF}_{2 a}$ on myogenic activity}

$\mathrm{PGF}_{2 \alpha}$ induced dose-related excitatory responses on all uterine tissues (Figs 4 and 5a). Full dose-response curves were completed in the presence of SQ29548 but no rightward shift was observed (data not shown); this lack of effect of the TP antagonist is shown in Fig. 5b. Regional variation in responsiveness to $\mathrm{PGF}_{2 \alpha}$ was observed in uterine tissue taken at oestrus $(P<0.05)$ (Fig. 4b) and dioestrus $(P<0.05)$ (Fig. $4 \mathrm{~d})$, with the upper uterine segments evoking a greater response than the lower segment. No regional variation in response was observed in gestational tissue (Fig. 4). In the lower segment, the response to $\mathrm{PGF}_{2 \alpha}$ in tissue taken during labour was significantly greater than in tissue taken during oestrus, metoestrus, dioestrus $(P<0 \cdot 001)$ and pro-oestrus $(P<0 \cdot 01)$ (Table 2). $\mathrm{PGF}_{2 \alpha}$ also evoked a greater response in tissue taken at late gestation compared with tissue taken during oestrus (lower segment, $P<0.001$; upper segment, $P<0 \cdot 01$ ), metoestrus (lower segment, $P<0 \cdot 01$; upper segment, $P<0 \cdot 05$ ), dioestrus (lower segment, $P<0 \cdot 01$ ) and pro-oestrus (lower segment, $P<0 \cdot 01)$. When responses to $\mathrm{PGF}_{2 \alpha}$ and U46619 were compared it was found that $\mathrm{PGF}_{2 \alpha}$ evoked a significantly greater response than
U46619 $(P<0 \cdot 05)$; this was observed in lower segment uterine tissue taken at late gestation (Table 2).

\section{Discussion}

The results of this study have demonstrated that mouse uterus is at its most active during labour, which is consistent with functionality during parturition. The uterus produces powerful and co-ordinated contractile activity in order to expel the foetuses at birth. This contractile activity is maintained equally along the length of the horn, which may facilitate the movement of the foetuses towards the cervix. The increased uterine activity observed during labour could be attributed to the high oestrogen concentrations observed towards term and the declining progesterone levels. Oestradiol-17 $\beta$ concentrations begin to rise on day 16 of gestation and continue to do so until day 20 (term), whilst peripheral progesterone concentrations begin to decline on day 17 of gestation reaching the lowest at term, day 20 (McCormack \& Greenwald 1974). The change in the oestrogen to progesterone ratio from day 18 to parturition could account for the differences in activity seen at late gestation and during labour. During labour, regional differences in myogenic activity are no longer observed; this could due to the high oestrogen levels associated with parturition. The whole of the uterine horn appears to be working in synchrony to aid the expulsion of the litter.

Oestrogen is thought to modulate several factors which contribute to the contractile state of the uterus during parturition, including oxytocin production, oxytocin receptor expression (Fang et al. 1996), prostaglandin receptor expression (Matsumoto et al. 1997) and connexin-43, the gap junction protein (Petrocelli \& Lye 1993). During labour, gap junctions are abundant in the mouse myometrium (Dahl \& Berger 1978). Myometrium taken from non-pregnant and pregnant mice was found to 

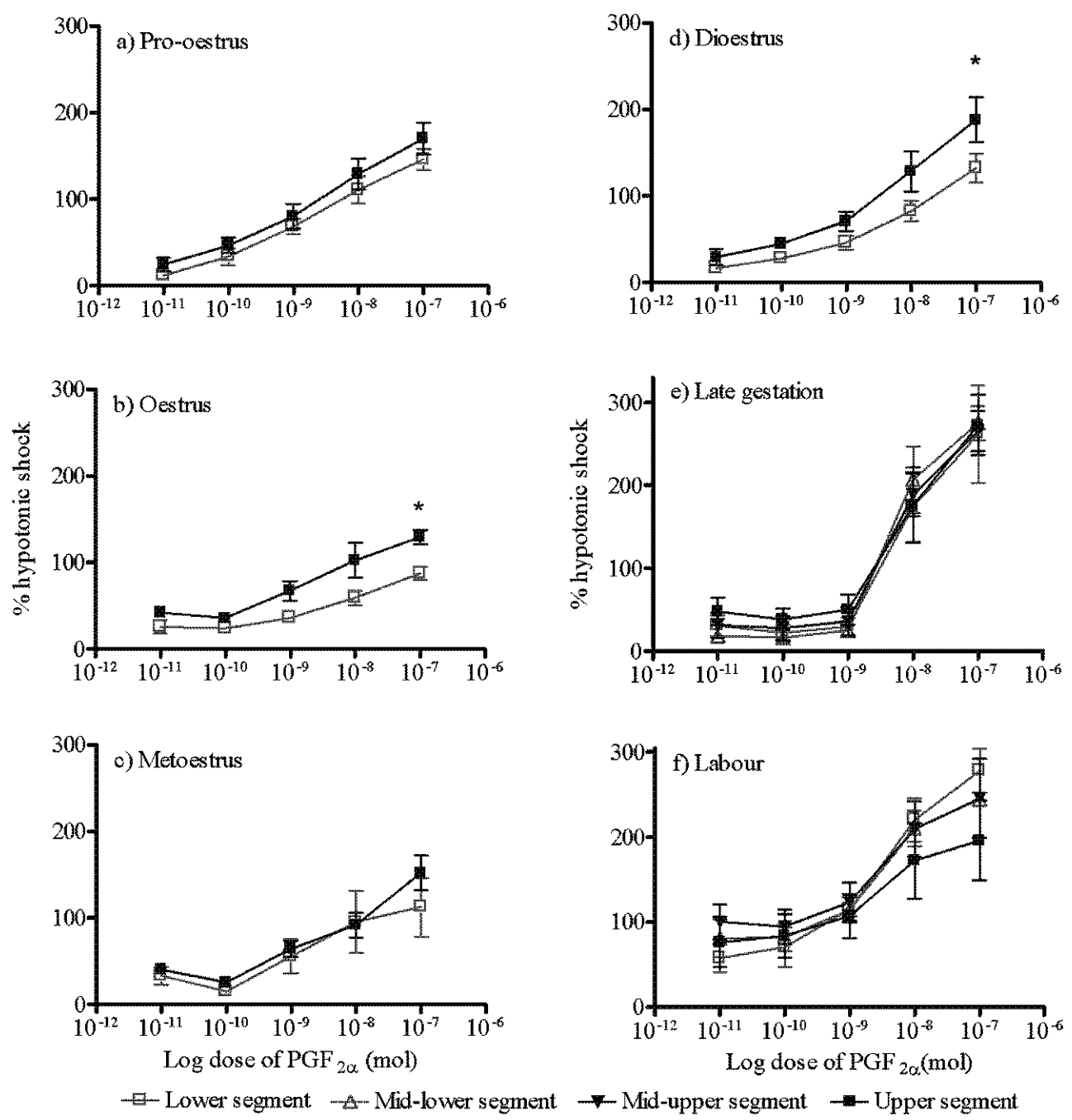

Figure 2 Dose-response curves to bolus doses of U46619 expressed as a percentage of a reference contraction induced by infusion of distilled water (hypotonic shock) in non-pregnant animals at (a) pro-oestrus, (b) oestrus, (c) metoestrus and (d) dioestrus (lower segment, open symbols and upper segment, solid symbols) and in gestational tissue at (e) gestation day 18 and (f) during parturition. Data are expressed as arithmetic means \pm S.E.M., $n=5-6$ and were statistically analysed using a two-way ANOVA with Bonferroni post hoc test. (d) Upper segment compared with lower $\left({ }^{*} P<0 \cdot 05\right)$. (e) Upper segment compared with lower $\left({ }^{* * *} P<0 \cdot 001\right)$ and mid-lower $\left({ }^{*} P<0 \cdot 05\right)$ and mid-upper compared with lower $\left({ }^{\# \#} P<0 \cdot 01\right)$.

have very few gap junctions (Dahl \& Berger 1978) which may explain the inability of these tissue samples to maintain their spontaneous activity.

During pregnancy, the uterus is associated with quiescence maintained by several inhibitory factors. Although at day 18 of gestation oestrogen levels have begun to rise, they have not yet peaked and quiescence appears to be maintained. Differences in activity with respect to reproductive state were also observed by Mackler et al. (1999); however, samples were not taken during parturition but after 6 h. Mackler et al. (1999) found that the postpartum uterus was most active which indicates that the uterus can maintain its contractile state for a least a day after parturition. They also found that tissue taken at oestrus was more active than tissue taken at late pregnancy. This is not consistent with the results reported here, but could be accounted for by the regional variations in activity observed in both non-pregnant and late gestational samples.

Hormone levels are also continuously changing during the oestrous cycle. Pro-oestrus is characterized by an increase in oestrogen levels that peak just before oestrus (Walmer et al. 1992). Progesterone concentrations are highest during metoestrus and dioestrus (Walmer et al. 1992). The change in the oestrogen and progesterone ratio would account for the increased myogenic activity observed at pro-oestrus and oestrus compared 


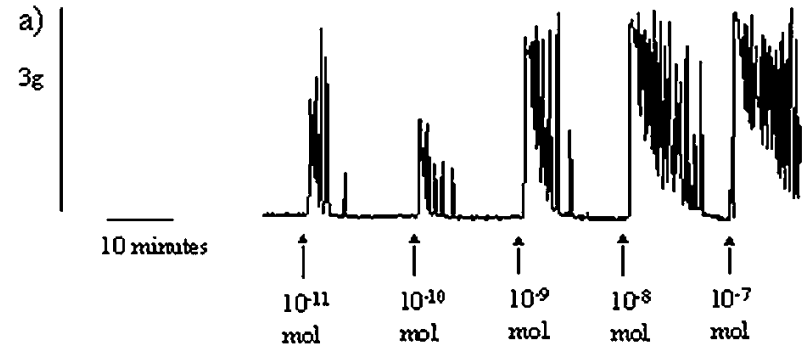

b)

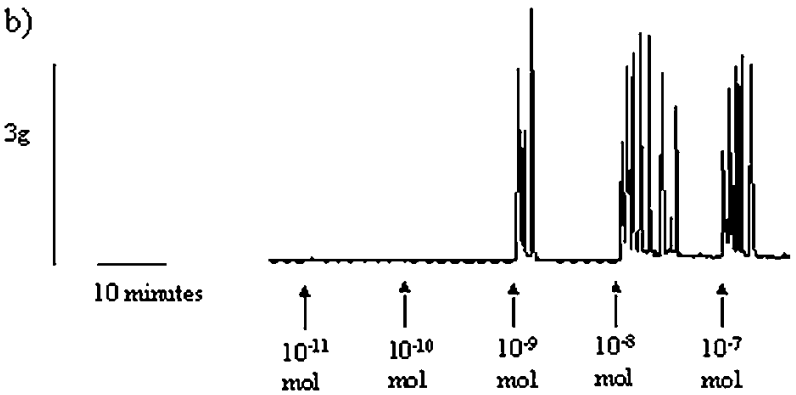

Figure 3 Sample traces showing activity of isolated uterine samples taken from non-pregnant animals at dioestrus to bolus doses of U46619 (a) alone and (b) in the presence of $0 \cdot 1 \mu \mathrm{M}$ SQ29548.

with metoestrus and dioestrus in the lower uterine segment.

Ovarian steroid production may account for the regional variation in myogenic activity observed in the uterine horn in non-pregnant mice and at late gestation. The activity was greatest in the upper segment of the uterine horn, which is nearest the site of production. This was particularly marked during dioestrus and metoestrus when myogenicity in the upper segment is six and eight times respectively greater than that in the lower segment. No regional variation in myogenicity was observed during oestrus; the high levels of oestrogen observed during pro-oestrus might have lasting contractile effects on the uterus, which may facilitate the transport of sperm along the uterine horn during oestrus. The site of sex steroid production may also account for regional differences observed during late gestation, with the uterine sample taken from the closest proximity to the ovaries being most active.

The contractile effect of U46619 was attenuated significantly in the presence of the selective TP antagonist SQ29548, confirming that the responses were mediated via the TP receptor. Our data have shown that there are no differences in the response to U46619 between the different stages of the oestrous cycle. This was comparable with data obtained from non-pregnant human myometrium that suggested that the response to U46619 is not influenced by menstrual status (Senchyna \& Crankshaw 1999).

Regional variations in response to U46619 observed during dioestrus and at late gestation may be due to a greater number of TP receptors in the ovarian region of the uterus at this stage of the oestrous cycle; however, to our knowledge, the quantitative distribution of TP receptors along the length of the mouse uterine horn has not been measured. The response to U46619 in non-pregnant human myometrium is not believed to be dependent on the excision site (Senchyna \& Crankshaw 1999); unfortunately this information is not available for myometrium from pregnant and labouring women at present.

In general, the response to U46619 was less influenced by hormonal milieu than the response to $\mathrm{PGF}_{2 \alpha}$. The role of thromboxane and the TP receptor in pregnancy and parturition is currently under further investigation in this laboratory.

Responses to $\mathrm{PGF}_{2 \alpha}$ were not altered in the presence of SQ29548, indicating that the excitation observed with $\mathrm{PGF}_{2 \alpha}$ is not due to any off-target TP activity. $\mathrm{PGF}_{2 \alpha}$ is believed to play a crucial role in the induction of parturition in the mouse (Tsuboi et al. 2002). FP knockout mice fail to undergo parturition (Sugimoto et al. 1999);

Table 2 Comparison of the uterine response to bolus doses of 100 nmol U46619 and PGF $_{2 \alpha}$ expressed as a percentage of the hypotonic shock in different reproductive states. Data are expressed as arithmetic means \pm S.E.M., $n=5-6$

\begin{tabular}{|c|c|c|c|c|}
\hline & \multicolumn{2}{|c|}{ Maximum response achieved with $100 \mathrm{nmol} U 46619$} & \multicolumn{2}{|c|}{ Maximum response achieved with $100 \mathrm{nmol}^{\mathrm{PGF}_{20}}$} \\
\hline Pro-oestrus & $140 \cdot 5 \pm 13 \cdot 4$ & $178 \cdot 0 \pm 14 \cdot 3$ & $145 \cdot 9 \pm 12 \cdot 4$ & $179 \cdot 8 \pm 18 \cdot 5$ \\
\hline Metoestrus & $131 \cdot 7 \pm 33 \cdot 0$ & $145 \cdot 6 \pm 17 \cdot 8$ & $112 \cdot 5 \pm 33 \cdot 7$ & $152 \cdot 0 \pm 20 \cdot 6$ \\
\hline Dioestrus & $149 \cdot 4 \pm 8 \cdot 6$ & $209 \cdot 7 \pm 25 \cdot 1^{b}$ & $132 \cdot 0 \pm 16 \cdot 6$ & $187 \cdot 8 \pm 25 \cdot 7$ \\
\hline Late gestation & $143 \cdot 6 \pm 49 \cdot 1^{\mathrm{a}}$ & $280 \cdot 6 \pm 36 \cdot 6^{c}$ & $262 \cdot 2 \pm 58 \cdot 5^{d}$ & $272 \cdot 9 \pm 36 \cdot 4^{f}$ \\
\hline
\end{tabular}

Data were statistically analysed using a two-way ANOVA with Bonferroni post hoc test. For the statistical analysis of anatomical differences see Figs 2 and 4. Differences between reproductive states (equivalent anatomical region): aresponse to U46619 in lower segment at late gestation compared with the responses to $\mathrm{PGF}_{\mathrm{a \alpha}}$ in both lower and upper segments $(P<0 \cdot 01)$; ${ }^{b}$ response to $\mathrm{U} 46619$ in upper segment during dioestrus compares with oestrus $(P<0 \cdot 05)$; ${ }^{C}$ response to U46619 in upper segment at late gestation compared with oestrus and metoestrus $(P<0 \cdot 01)$; ${ }^{d}$ response to $P G F_{\text {a }}$ in lower segment at late gestation compared

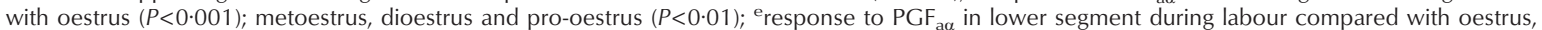
metoestrus, dioestrus $(P<0 \cdot 001)$ and pro-oestrus $(P<0 \cdot 01)$; ${ }^{f}$ response to $\mathrm{PGF}_{\text {a }}$ in upper segment at late gestation compared with oestrus $(P<0 \cdot 01)$ and metoestrus $(P<0 \cdot 05)$. 

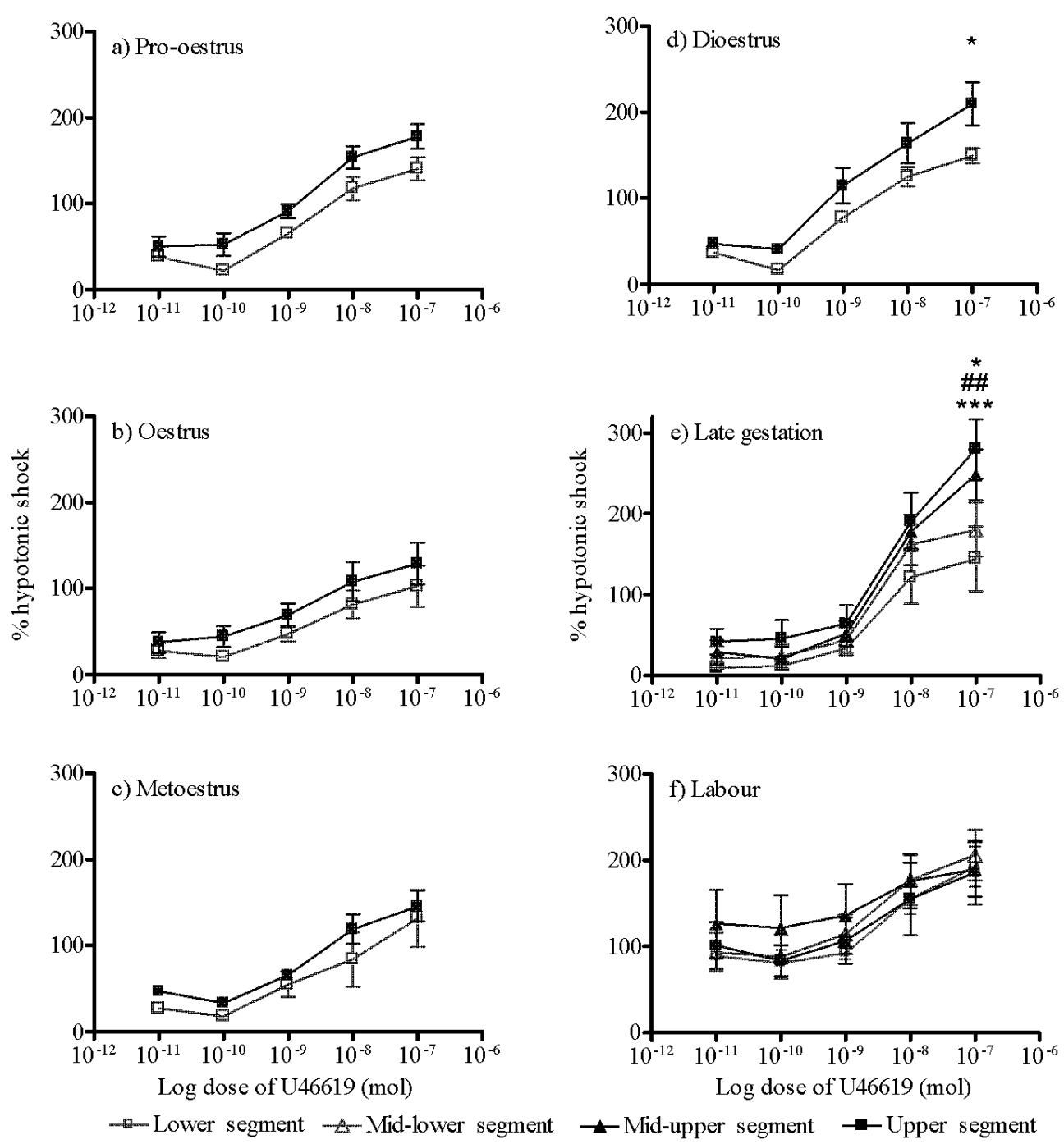

Figure 4 The dose-response of bolus doses of $\mathrm{PGF}_{2 \alpha}$ expressed as a percentage of a reference contraction induced by infusion of distilled water (hypotonic shock) in non-pregnant animals at (a) pro-oestrus, (b) oestrus, (c) metoestrus and (d) dioestrus (lower segment, open symbols and upper segment, solid symbols) and in gestational tissue at (e) gestation day 18 and (f) during parturition. Data are expressed as arithmetic mean \pm S.E.M., $n=5-6$ and were statistically analysed using a two-way ANOVA with Bonferroni post hoc test. Upper compared with lower $\left({ }^{*} P<0 \cdot 05\right)$.

this is due, however, to the role of $\mathrm{PGF}_{2 \alpha}$ in luteolysis (Horton \& Poyser 1976) rather than simply its contractile effects on the uterus. The luteolytic function of $\mathrm{PGF}_{2 \alpha}$ appears to be less crucial during the oestrous cycle (Sugimoto et al. 1999). The importance of uterine FP receptor activation in the initiation and progression of parturition is not yet fully understood, but it is known that uterine FP receptor mRNA and uterine tissue concentrations of $\mathrm{PGF}_{2 \alpha}$ increase in the mouse at late gestation (Cook et al. 2003). The similar responses to $\mathrm{PGF}_{2 \alpha}$ observed at late gestation and during labour are consistent with upregulation of the FP receptor by day 18 of gestation and expression remaining high during parturition. This is reaffirmed by the significant increase in responsiveness seen in tissue taken during late gestation and labour compared with tissue taken from non-pregnant animals.

The results have demonstrated that the uterine contractile response to $\mathrm{PGF}_{2 \alpha}$ varied anatomically in uterine tissue taken during oestrous and dioestrous stages, but no differences were observed in gestational tissue. These findings are similar to those observed in the non-pregnant rat where the uterus demonstrates regional variation in responsiveness to $\mathrm{PGF}_{2 \alpha}$ (Oropeza et al. 2002). These 

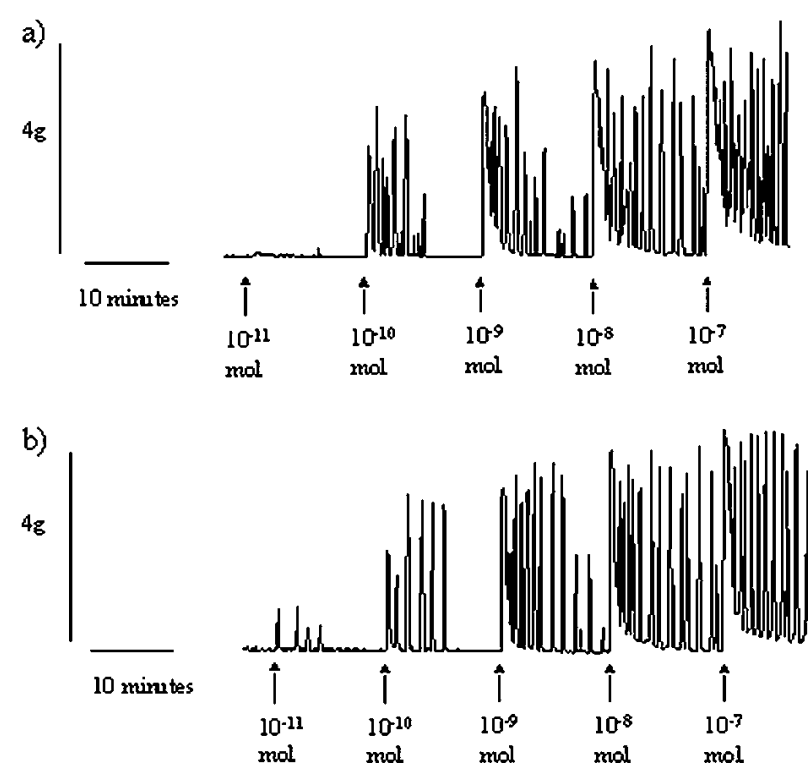

Figure 5 Sample traces showing activity of isolated uterine samples taken from non-pregnant animals at dioestrus during bolus doses of $\mathrm{PGF}_{2 \alpha}$ (a) alone and (b) in the presence of $0 \cdot 1 \mu \mathrm{M}$ SQ29548.

studies suggest that the FP receptor population is greater in the upper region of the uterus; topographical distribution of prostanoid receptors are currently being investigated on human myometrium.

It is possible that differences in responsiveness to both agonists may not be solely attributable to changes in receptor density but could be influenced by other factors, for example, changes in gap junction numbers. The expression of connexin 43 is regulated by prostaglandins and steroids (Garfield et al. 1988, Kilarski et al. 2000). Increased responsiveness could also be affected by changes in signal transduction pathways.

These data have demonstrated that the hormonal milieu and the anatomical region influence uterine activity and responsiveness. Such factors must be considered when making inter-species comparisons and extrapolating results to predict in vivo responses.

\section{Acknowledgements}

The authors would like to thank Dr Dave Jerwood for his good humour and sound statistical advice. A L G was supported by Allergan Inc. The authors declare that there is no conflict of interest that would prejudice the impartiality of this scientific work.

\section{References}

Abramovitz $\mathrm{M}$, Carrière $\mathrm{M}$, Lamontagne $\mathrm{S}$, Denis $\mathrm{D}$, Adam $\mathrm{M}$, Boie Y, Sawyer N, Godbout C \& Rochette C 2000 The utilization of recombinant prostanoid receptors to determine the affinities and selectivities of prostaglandins and related analogs. Biochimica et Biophysica Acta 1483 285-293.

Brodt-Eppley J \& Myatt L 1999 Prostaglandin receptors in lower segment myometrium during gestation and labor. Obstetics and Gynecology 93 89-93.

Chen J, Woodward DF, Coleman RA, Jones RL \& Lydford SJ 2001 Prostanoid receptor assays Unit 4.18. In Current Protocols in Pharmacology, vol. 1, Ch 4, unit 4.18. Eds SJ Enna, M. Williams, JW Ferkany, T Kenakin, PR Porsolt \& JP Sullivan. New York, NY, USA: John Wiley \& Sons, Inc.

Cook JL, Anderson KI, Olson DM, Shallow MC \& Zaragoza DB 2003 Mouse placental prostaglandins are associated with uterine activation and the timing of birth. Biology of Reproduction 68 579-587.

Crankshaw DJ 2001 Pharmacological techniques for the in vitro study of the uterus. Journal of Pharmacology and Toxicology Methods $45123-140$.

Dahl G \& Berger W 1978 Nexus formation in the myometrium during parturition and induced by estrogen. Cell Biology International Reports 2 381-387.

Duckworth N, Marshall K \& Clayton JK 2002 An investigation of the effect of the prostaglandin EP2 receptor agonist, butaprost, on the human isolated myometrium from pregnant and non-pregnant women. Journal of Endocrinology 172 263-269.

Fang X, Wong S \& Mitchell BF 1996 Relationships among sex steroids, oxytocin, and their receptors in the rat uterus during late gestation and at parturition. Endocrinology 137 3213-3219.

Fox R \& Laird C 1970 Sexual cycles. In Reproduction and Breeding Techniques for Laboratory Animals, pp 107-122. Ed L Febiger. Philadelphia, PA, USA: ESE Hafez.

Fuchs AR 1969 Uterine activity in late pregnancy and during parturition in the rat. Biology of Reproduction 1 344-353.

Garfield RE, Blennerhassett MG \& Miller SM 1988 Control of myometrial contractility: role and regulation of gap junctions. Oxford Reviews in Reproductive Biology 10 436-490.

Hirata M, Narumiya S, Ushikubi F, Kakizuka A \& Aizawa M 1994 Molecular characterization of a mouse prostaglandin D receptor and functional expression of the cloned gene. PNAS 91 11192-11196.

Honda A, Irie A, Watabe A, Narumiya S, Sugimoto Y, Namba T, Negishi M \& Ichikawa A 1993 Cloning and expression of a cDNA for mouse prostaglandin E receptor EP2 subtype. Journal of Biological Chemistry 268 7759-7762.

Horton EW \& Poyser NL 1976 Uterine luteolytic hormone: a physiological role for prostaglandin F2 alpha. Physiological Reviews $56595-651$.

Hutchinson J, Marshall K \& Senior J 2003 Preliminary studies using a putative FP-receptor antagonist, AL-8810, on isolated mouse uterus. British Journal of Pharmacology 1 038P.

Kennedy F, Marshall K \& Senior J 1994 Characterisation of the thromboxane (TP) receptor population in isolated mouse uterus. British Journal of Pharmacology 112 432P.

Kilarski WM, Roomans GM, Hongpaisan J \& Semik D 2000 Effect of progesterone and oestradiol on expression of connexin 43 in cultured human myometrium cells. Folia Histochemica et Cytobiologica 38 3-9.

Mackler AM, Yellon SM, Ducsay CA \& Veldhuis JD 1999 Maturation of spontaneous and agonist-induced uterine contractions in the peripartum mouse uterus. Biology of Reproduction 61 873-878.

Matsumoto T, Mori T, Kotani M, Tanaka I, Sagawa N, Yoshida M, Mukoyama M \& Nakao K 1997 The prostaglandin E2 and F2 alpha receptor genes are expressed in human myometrium and are down-regulated during pregnancy. Biochemical and Biophysical Research Communications 238 838-841. 
McCormack JT \& Greenwald GS 1974 Progesterone and oestradiol-17 $\beta$ concentrations in the peripheral plasma during pregnancy in the mouse. Journal of Endocrinology 62 101-107.

Namba T, Honda A, Narumiya S, Hayashi Y, Negishi M, Sugimoto Y, Hirata M, Watabe A \& Ichikawa A 1992 Mouse thromboxane A2 receptor: cDNA cloning, expression and northern blot analysis. Biochemical and Biophysical Research Communications 184 1197-1203.

Namba T, Negishi M, Kakizuka A, Narumiya S, Oida H, Sugimoto Y \& Ichikawa A 1994 cDNA cloning of a mouse prostacyclin receptor. Multiple signaling pathways and expression in thymic medulla. Journal of Biological Chemistry 269 9986-9992.

Nishigaki N, Sugimoto Y, Ichikawa A, Namba T, Negishi M, Honda A \& Narumiya S 1995 Identification of prostaglandin E receptor 'EP2' cloned from mastocytoma cells EP4 subtype. FEBS Letters 364 339-341.

Ogletree ML, Haslanger MF, Nakane M, Harris DN \& Greenberg R 1985 Pharmacological actions of SQ 29,548, a novel selective thromboxane antagonist. Journal of Pharmacology and Experimental Therapentics 234 435-441.

Oropeza MV, Campos MG, Ponce Monter H \& Reynoso Isla M 2000 The ovarian and cervical regions of the rat uterus display a different contractile response to serotonin and prostaglandin F2 alpha. I. The estrous cycle. Life Science 66 PL345-PL351.

Oropeza MV, Palma-Aguirre JA, Campos MG, Ponce-Monter H \& Villanueva-Tello T 2002 Anatomical differences in uterine sensitivity to prostaglandin $\mathrm{F}$ ( 2 alpha) and serotonin in non-pregnant rats. European Journal of Pharmacology 446 161-166.

Petrocelli T \& Lye SJ 1993 Regulation of transcripts encoding the myometrial gap junction protein, connexin-43, by estrogen and progesterone. Endocrinology 133 284-290.

Sales ME, Tenenbaum A, Borda ES, Baraao RI \& Rumi LS 1992 Differential PGE2 and cAMP production by allogeneic and syngeneic pregnant mice uteri. Prostaglandins, Leukotrienes and Essential Fatty Acids 47 297-300.

Senchyna M \& Crankshaw DJ 1999 Operational correlates of prostanoid TP receptor expression in human non-pregnant myometrium are unaffected by excision site or menstrual cycle status of the donor. British Journal of Pharmacology 128 1524-1528.

Senior J, Baxter GS, Clayton JK, Marshall K \& Sangha R 1991 In vitro characterization of prostanoid $\mathrm{EP}$-receptors in the non-pregnant human myometrium. British Journal of Pharmacology $102747-753$.

Senior J, Marshall K, Clayton JK, Sangha R \& Baxter GS 1992 In vitro characterization of prostanoid FP-, DP-, IP- and TP-receptors on the non-pregnant human myometrium. British Journal of Pharmacology 107 215-221.

Sugimoto Y, Negishi M, Hayashi Y, Narumiya S, Namba T, Honda A \& Ichikawa A 1992 Cloning and expression of a cDNA for mouse prostaglandin E receptor EP3 subtype. Journal of Biological Chemistry 267 6463-6466.

Sugimoto Y, Irie A, Kakizuka A, Katsuyama M, Hasumoto K, Namba T, Ichikawa A, Negishi M \& Narumiya S 1994 Cloning and expression of a cDNA for mouse prostaglandin F receptor. Journal of Biological Chemistry 269 1356-1360.

Sugimoto Y, Ichikawa A, Narumiya S, Segi E \& Tsuboi K 1999 Female reproduction in mice lacking the prostaglandin $\mathrm{F}$ receptor. Roles of prostaglandin and oxytocin receptors in parturition. Advances in Experimental Medical Biology 449 317-321.

Thomas DW, Mannon RB, Mannon PJ, Latour A, Loiver JA, Hoffman M, Smithies O, Koller BH \& Coffman TM 1998 Coagulation defects and altered hemodynamic responses in mice lacking receptors for thromboxane $\mathrm{A}_{2}$. Journal of Clinical Investigation 102 1994-2001.

Tsuboi K, Sugimoto Y \& Ichikawa A 2002 Prostaglandin E2 and F2 in mouse reproduction. International Congress Series 1233 397-404.

Walmer DK, Nelson KG, Wrona MA \& Hughes CL 1992 Lactoferrin expression in the mouse reproductive tract during the natural estrous cycle: correlation with circulating estradiol and progesterone. Endocrinology 131 1458-1466.

Watabe A, Namba T, Ichikawa A, Irie A, Ito S, Sugimoto Y, Honda A, Negishi M \& Narumiya S 1993 Cloning and expression of cDNA for a mouse EP1 subtype of prostaglandin E receptor. Journal of Biological Chemistry 268 20175-20178.

Wikland M, Lindblom B \& Wiqvist N 1984 Myometrial response to prostaglandins during labor. Gynecologic \& Obstetic Investigation $17131-138$

Received 21 November 2005

Accepted 30 November 2005 